\title{
The Impact of Leptospirosis Health Education Module (LHEM) on Changes of Knowledge, Attitude and Practice (KAP) among Army Personnel in Northeastern Malaysia
}

\author{
Y. Siti Sara1, B. D. Aziah"2* (), Y. N. Azwany², S. Mohd Nazri², W. M. Zahiruddin², A. Nabilah³, \\ H. Siti Asma'3, I. Zaliha ${ }^{4}$ \\ ${ }^{1}$ Public Health Division, Selangor State Health Department, Ministry of Health, Selangor, Malaysia \\ ${ }^{2}$ Department of Community Medicine, School of Medical Sciences, Universiti Sains Malaysia, Kelantan, Malaysia \\ ${ }^{3}$ Department of Medical Microbiology \& Parasitology, School of Medical Sciences, Universiti Sains Malaysia, Kelantan, Malaysia \\ ${ }^{4}$ Population Health \& Preventive Medicine Discipline, Faculty of Medicine, Universiti Teknologi MARA, Selangor, Malaysia \\ Email: *aziahkb@usm.my
}

How to cite this paper: Sara, Y.S., Aziah, B.D., Azwany, Y.N., Nazri, S.M., Zahiruddin, W.M., Nabilah, A., Asma', H.S. and Zaliha, I. (2020) The Impact of Leptospirosis Health Education Module (LHEM) on Changes of Knowledge, Attitude and Practice (KAP) among Army Personnel in Northeastern Malaysia. Open Journal of Epidemiology, 10, 146-157.

https://doi.org/10.4236/ojepi.2020.102013

Received: February 12, 2020

Accepted: May 4, 2020

Published: May 7, 2020

Copyright $\odot 2020$ by author(s) and Scientific Research Publishing Inc. This work is licensed under the Creative Commons Attribution International License (CC BY 4.0).

http://creativecommons.org/licenses/by/4.0/ (c) (i) Open Access

\begin{abstract}
Community-based interventions in prevention and control of leptospirosis, have been uniformly unsuccessful. Individual counseling and health education play an important role in the prevention and control of the disease. The aim of this study was to compare the effect of intervention on the knowledge, attitude and practice (KAP) score on leptospirosis among the army personnel after receiving a health education given. A validated questionnaire was used to assess knowledge, attitude and practice at pre- and post-intervention. A total of 188 army personnel from the two camps involved in this study with 94 respondents in control and intervention groups respectively. Leptospirosis Health Education Module (LHEM) was given to the intervention group. There was significant improvement in knowledge score before and after intervention done (mean difference $=24.25,95 \%$ CI: 21.93, 26.56; $\mathrm{p}<0.001$ ) in the intervention camp. However, for the control camp, there was no significant improvement in knowledge score before and after intervention (mean difference $=4.02,95 \%$ CI: $1.55,6.50 ; \mathrm{p}=0.200$ ). For the intervention effect, the subjects in the control group had a significantly lower knowledge score between as compared to the subjects in the intervention group (mean difference $=-14.13,95 \%$ CI: $-15.82,-12.45 ; \mathrm{p}<0.001)$. While for the attitude score, there was significant improvement in attitude score before and after intervention in the intervention camp (mean difference $=3.82,95 \%$ CI: 2.47 , 5.17; $\mathrm{p}<0.001$ ). However, for the control camp, there was no significant improvement in attitude score before and after intervention (mean difference $=$
\end{abstract}


$0.42,95 \% \mathrm{CI}:-0.72,1.55 ; \mathrm{p}>0.05)$. For the intervention effect, the subjects in intervention group had significantly higher mean attitude score as compared to the subjects in control group (mean difference $=-2.12,95 \% \mathrm{CI}:-2.99$, $-1.24 ; \mathrm{p}<0.001)$. While for practice score, there was a significant improvement in score before and after intervention done (mean difference $=3.44$, 95\% CI: $1.80,5.07 ; \mathrm{p}<0.001$ ) in the intervention camp. However, for the control camp, there was no significant improvement in practice score before and after intervention (mean difference $=0.76,95 \% \mathrm{CI}:-0.47,1.98 ; \mathrm{p}>0.05$ ). For the intervention effect regardless of time, the subjects in intervention group had significantly higher mean practice score as compared to the subjects in control group (mean difference $=4.16,95 \% \mathrm{CI}: 2.80,5.52 ; \mathrm{p}<0.001$ ). The leptospirosis health education module was found to cause improvement in KAP score in the intervention group.

\section{Keywords}

Army Personnel, LHEM, Knowledge, Attitude, Practice

\section{Introduction}

Leptospirosis is a zoonotic bacterial disease caused by infection of the bacteria which belongs to genus leptospira that affects human as well as other mammals, birds, amphibians and reptiles. It can be transmitted from animals to humans [1] [2]. Humans are usually the incidental hosts [3] [4].

Knowledge, attitude and practice (KAP) surveys are a common strategy done by researchers to gather the information on leptospirosis and to assess the safe work practice among populations at risk [5]. Researchers around the world especially those who are at the endemic region for leptospiral infections, had done various researches to assess the knowledge of the community and high-risk groups [6]. Unfortunately review of literature revealed that very little information regarding KAP study on leptospirosis among army personnel.

The role of counseling and health education plays an important role in the prevention and control of leptospirosis. Military recruits travelling or involved in the operation or training in endemic areas for leptospirosis should be informed about high-risk activities for acquisition of infection. They should be advised to wear protective waterproof clothes and boots, to avoid submersion and consumption of river water and to cover cuts and abrasions with waterproof dressings to minimize exposure to contaminated environments [7]. They should take extra precautions if the operational or training areas were recently affected by floods. Drinking water should be purified by boiling and treated with chlorine. Filtration of water might not be effective due to the size of the organism and can pass through $0.45 \mu \mathrm{M}$ filters [1]. The aim of our study is to compare the effect of LHEM on the knowledge, attitude and practice (KAP) score on leptospirosis among the army personnel in Northeastern Malaysia. 


\section{Materials and Methods}

\subsection{Description of Intervention}

The leptospirosis health education module (LHEM) consisted of a lecture, giving printed materials on leptospirosis for example booklet, phamplets and poster and followed by questions and answers session, related to leptospirosis and its prevention.

The development of Leptospirosis Health Education Module (LHEM) took five months to be completed. The initial stage involved literature searching on the topic of leptospirosis, its associated factors and preventive and control measures. The nominal group technique was used for selection of health education material and content. The draft of the booklets, pamphlets and poster were thoroughly discussed in a three days workshop and being evaluated. The presentation and graphic input were also done with the assistance of a Graphic Officer in Graphic Department, Universiti Sains Malaysia. Field testing was done and the final draft of the module was sent to Literature Centre for language and grammar check before printing.

Lecture on leptospirosis, its associated factors and preventive measures given by a doctor. The important elements of the lecture were an elaboration of leptospirosis, its associated factors, clinical presentations and preventive measures of leptospirosis among army. This was an interactive lecture session on leptospirosis among army and preventive measures at the workplace among army personnel.

The army personnel in the intervention group were given the intervention while the control group was not given any intervention. The intervention was given in one day program called Leptospirosis Awareness Day. It consisted of health talk on leptospirosis among army personnel, briefing on booklet, pamphlets and poster as well as the health exhibition.

\subsection{Participants}

Two army camps were randomly selected from all the four army camps in Northeastern State of Malaysia involving 188 subjects. Camp A was selected as the intervention group while Camp B was selected as the control group. Sample size was estimated using PS Software Version 3.0 [8], based on a study in Malaysia [5] as shown in Table 1.

Table 1. Sample size estimation.

\begin{tabular}{ccccc}
\hline Variables & SD & $\begin{array}{c}\text { Detectable } \\
\text { mean difference }\end{array}$ & $\begin{array}{c}\text { Calculated } \\
\text { sample size }\end{array}$ & $\begin{array}{c}\text { After considering } \\
\text { 20\% drop out }\end{array}$ \\
\hline Total knowledge score & 8.48 & 4 & $\begin{array}{c}72 \text { for each group } \\
\text { Total }=144\end{array}$ & 173 \\
Total attitude score & 10.96 & 5 & $\begin{array}{c}76 \text { for each group } \\
\text { Total }=152\end{array}$ & 182 \\
Total practice score & 13.31 & 6 & $\begin{array}{c}78 \text { for each group } \\
\text { Total }=156\end{array}$ & 188 \\
\hline
\end{tabular}


A total of 94 army personnel was selected to be in intervention group while another 94 army personnel were selected to be in control group based on sample size calculation. The inclusion criteria were the army personnel who had been in service for at least six months and involved in the training and operational activities. While those who were not in base camp during study period, army personnel who were doing the administrative work and did not involved in the training or operational activities were excluded. All of them consented to take part in the study.

\subsection{Measurements}

The army personnel's knowledge, attitude and practice (KAP) were measured using a validated instrument (Knowledge, Attitude and Practice Questionnaire) [9]. There were a total of 67 questions in this questionnaire whereby 43 items were in knowledge domain, 12 items were in attitude domain while practice domain had 12 items. The knowledge questions represented seven constructs (causes, occupational risk groups, mode of transmissions, symptoms, complications, risk factors and prevention and control measures) while the attitude and practice questions corresponded to two constructs (positive attitude (off work) and positive attitude at workplace) and (safe work practice and general practice (off work)) respectively. The internal consistency values of knowledge, attitude and practice items were $0.912,0.611$ and 0.594 respectively.

Each knowledge item had three answer options. Each correct response was allocated 3 points, incorrect response was allocated 1 point while do know response was allocated 2 points. Questions on attitude were designed to be answered using Likert scale, which were Strongly agree, Agree, Not sure, Not agree, Strongly not agree. For positive attitude item, scores of “5”, “4”, “3”, “2” and "1" were used for "Strongly agree", "Agree", "Not sure", "Not agree”, "Strongly not agree" respectively. For negative attitude, the above scoring was reversed. The information that was acquired is important in understanding the respondents' attitude in health seeking and use of preventive measures. The practice domain was also designed to be answered using Likert scales, which were "always", "often", "sometimes", "seldom" and "never". For good practice item, scores of " 5 ", " 4 ", “ 3 ", " 2 " and " 1 " were used for "always", "often", "sometimes”, "seldom" and "never" respectively. For bad practice, the scoring was reversed. The practice domain assessed the respondent's practice in term of safe work practice while they were at work as well as general practices while they were not at work. The practice domain was done to assess the practices of the respondents with regards to leptospirosis.

\subsection{Procedures}

This study was approved by Research and Ethics Committee (Human), School of Medical Sciences, Health Campus, Universiti Sains Malaysia and was funded by Research University Grant (1001/PPSP/812106). Permission to conduct study in 
each participating army-based camp was obtained from the Medical Service Unit, Malaysian Armed Forces. A detailed explanation about the study was given to the respondents before the study begins. A written informed consent form was given once the respondents agreed for them to sign.

The KAP scores before intervention were taken as the pre intervention values. Six weeks after Leptospirosis Awareness Day and cessation of the LHEM, the post intervention values were taken using same questionnaire. The evaluation of the program was done by comparing the pre and post intervention KAP score for the intervention and the control groups.

\subsection{Data Analysis}

To determine the effect of LHEM, repeated measures analysis of variance (RM ANOVA) was used to compare the changes in the outcome measurement before and after intervention in the control and intervention groups. ANOVA [10] was used to show the difference of mean KAP score in control and intervention group. For this analysis, two designs were used in repeated measure [11].

1) Within group design (time effect)

It involves comparison of the same subjects at different times. In this study, within group difference was done in each group; intervention group and control group. One comparison was done within each group which was pre intervention and post intervention.

2) Between group design regardless of time (intervention effect)

It involves comparing two different groups, regardless of time. In this study, the groups were intervention group and control group.

\section{Results}

\subsection{Mean KAP Score}

Of the 188 army personnel participated in the study, 94 subjects were in intervention and control group respectively. All the eligible army personnel consented to participate in this study. All respondents were Malay males with the mean age of 29.2 (7.1) years old and ranged from 18 to 51 years old. The mean duration of employment was 11.5 (7.7) years. For level of education, $68.3 \%$ of the respondents had received upper secondary school and above.

Table 2 showed the mean knowledge score before and after intervention in both intervention and control camps. The mean knowledge score was higher among the subjects in the control camp than the subjects in the intervention camp. However, the mean knowledge score at baseline was not significantly different between intervention and control camps (mean difference $=-1.64,95 \%$ CI: $-4.10,0.82 ; \mathrm{p}=0.191)$.

Table 3 showed the mean attitude score before and after intervention in both intervention and control camps. The baseline mean attitude score for both intervention and control camps was not significantly different (mean difference $=$ $0.24,95 \%$ CI: $-1.23,1.70 ; \mathrm{p}=0.753$ ). 
Table 2. Knowledge score in intervention and control camps before and after the intervention $(\mathrm{n}=188)$.

\begin{tabular}{ccc}
\hline \multirow{2}{*}{ Variables } & Intervention Camp & Control Camp \\
\cline { 2 - 3 } & Mean (SD) & Mean (SD) \\
\hline Pre intervention & $97.97(0.82)$ & $99.61(0.94)$ \\
Post intervention & $122.21(0.81)$ & $103.63(0.83)$ \\
\hline
\end{tabular}

Table 3. Attitude score in intervention and control camps before and after the intervention $(\mathrm{n}=188)$.

\begin{tabular}{ccc}
\hline \multirow{2}{*}{ Variables } & Intervention Camp & Control Camp \\
\cline { 2 - 3 } & Mean (SD) & Mean (SD) \\
\hline Pre intervention & $52.10(0.56)$ & $51.86(0.49)$ \\
Post intervention & $55.91(0.44)$ & $52.28(0.39)$ \\
\hline
\end{tabular}

Mean practice score before and after intervention in both intervention and control camps was shown in Table 4. The mean practice score at baseline was not significantly different between intervention and control camps (mean difference $=2.07,95 \%$ CI: $0.33,3.80 ; \mathrm{p}=0.200)$.

\subsection{Comparison Knowledge Score}

Maunchly's test of Sphericity for within group changes of knowledge score based on time indicated that the assumption of sphericity was violated. Based on Multivariate test (Wilks' Lambda $\mathrm{F}(1,187)=157.12, \mathrm{p}<0.001$, there were significant effect of time on changes of knowledge score within the two camps. For the intervention camp, there was significant improvement in knowledge score before and after intervention done (mean difference $=24.25,95 \%$ CI: $21.93,26.56 ; \mathrm{p}<$ 0.001). However, for the control camp, there was no significant improvement in knowledge score before and after intervention (mean difference $=4.02,95 \% \mathrm{CI}$ : $1.55,6.50 ; \mathrm{p}=0.200$ ). The findings for the time effect on both camps were shown in Table 5.

Test of between-subjects effects indicated that there was a significant mean difference in knowledge score between the intervention and control groups $(\mathrm{F}(1$, $187)=99.07, \mathrm{p}<0.001)$. Subsequent comparison showed that the subjects in control group had significantly lower mean knowledge score as compared to the subjects in intervention group (mean difference $=-14.13,95 \%$ CI: $-15.82,12.45$; $\mathrm{p}<0.001$ ). Table 6 showed the comparison of knowledge score between intervention and control camps.

\subsection{Comparison Attitude Score}

Maunchly's test of Sphericity for within group changes of attitude score based on time indicated that the assumption of sphericity was violated. Based on Multivariate test (Wilks' Lambda $F(1,187)=21.18, \mathrm{p}<0.001$, there were significant effect 
Table 4. Practice score in intervention and control camps before and after the intervention $(\mathrm{n}=188)$.

\begin{tabular}{ccc}
\hline \multirow{2}{*}{ Variables } & Intervention Camp & Control Camp \\
\cline { 2 - 3 } & Mean (SD) & Mean (SD) \\
\hline Pre intervention & $49.96(0.62)$ & $47.89(0.62)$ \\
Post intervention & $53.39(0.66)$ & $47.14(0.53)$ \\
\hline
\end{tabular}

Table 5. Comparison of knowledge score between intervention and control camps based on time $(\mathrm{n}=188)$.

\begin{tabular}{ccccc}
\hline & \multicolumn{2}{c}{ Intervention } & \multicolumn{2}{c}{ Control } \\
\cline { 2 - 5 } Comparison & $\begin{array}{c}\text { Mean difference } \\
(95 \% \mathrm{CI})\end{array}$ & p-value & $\begin{array}{c}\text { Mean difference } \\
(95 \% \mathrm{CI})\end{array}$ & $\mathrm{p}$-value \\
& 24.25 & & 4.02 & 0.200 \\
Post-pre intervention & $(21.93,26.56)$ & $<0.001$ & $(1.55,6.50)$ & \\
\hline
\end{tabular}

Repeated measures ANOVA within group analysis were applied followed by pairwise comparison with confidence interval adjustment.

Table 6. Comparison of knowledge score between intervention and control camps regardless of time (treatment effect) $(n=188)$.

\begin{tabular}{ccc}
\hline Comparison & Mean difference $(95 \% \mathrm{CI})$ & p-value \\
\hline Control-Intervention & $-14.13(-15.82,-12.45)$ & $<0.001$ \\
\hline
\end{tabular}

F-stat $(\mathrm{df})=99.07(1,186), \mathrm{p}$-value $\leq 0.001$. Repeated measures ANOVA between group analysis was applied followed by pairwise comparison. Assumption of normality, homogeneity of variances and compound symmetry were checked and fulfilled. Level of significance was set at 0.05 (two-tailed).

of time on changes of attitude score within the groups. For the intervention camp, there was significant improvement in attitude score before and after intervention done (mean difference $=3.82$, 95\% CI: 2.47, 5.17; $\mathrm{p}<0.001$ ). However, for the control camp, there was no significant improvement in attitude score before and after intervention (mean difference $=0.42,95 \% \mathrm{CI}:-0.72,1.55 ; \mathrm{p}=$ 0.471). The findings for the time effect on both camps were shown in Table 7.

Test of between-subjects effects indicated that there was a significant mean difference in attitude score between the intervention and control group $(\mathrm{F}(1$, $186)=14.92, \mathrm{p}<0.001)$. Subsequent comparison showed that the subjects in intervention group had significantly higher mean knowledge score as compared to the subjects in control group (mean difference $=-2.12,95 \% \mathrm{CI}:-2.99,-1.24 ; \mathrm{p}$ $<0.001$ ). Table 8 showed the comparison of attitude score between intervention and control camps.

\subsection{Comparison Practice Score}

Maunchly's test of Sphericity for within group changes of practice score based on time indicated that the assumption of sphericity was violated. Based on Multivariate test (Wilks' Lambda $F(1,187)=6.25, \mathrm{p}<0.05$, there were significant effect on time on changes of practice score within the intervention and control 
Table 7. Comparison of attitude score between intervention and control camps based on time $(\mathrm{n}=188)$.

\begin{tabular}{ccccc}
\hline \multirow{2}{*}{ Comparison } & \multicolumn{2}{c}{ Intervention } & \multicolumn{2}{c}{ Control } \\
\cline { 2 - 5 } & $\begin{array}{c}\text { Mean difference } \\
(95 \% \mathrm{CI})\end{array}$ & $\mathrm{p}$-value & $\begin{array}{c}\text { Mean difference } \\
(95 \% \mathrm{CI})\end{array}$ & $\mathrm{p}$-value \\
Post-pre intervention & 3.82 & & 0.42 & 0.471 \\
\hline
\end{tabular}

Repeated measures ANOVA within group analysis were applied followed by pairwise comparison with confidence interval adjustment.

Table 8. Comparison of attitude score between intervention and control camps regardless of time (intervention effect) $(\mathrm{n}=188)$.

\begin{tabular}{ccc}
\hline Comparison & Mean difference $(95 \% \mathrm{CI})$ & p-value \\
\hline Control-Intervention & $-2.12(-2.99,-1.24)$ & $<0.001$ \\
\hline
\end{tabular}

F-stat $(\mathrm{df})=14.92(1,186)$, p-value $\leq 0.001$. Repeated measures ANOVA between group analysis was applied. Assumption of normality, homogeneity of variances and compound symmetry were checked and fulfilled. Level of significance was set at 0.05 (two-tailed).

groups. For the intervention camp, there was significant improvement in practice score before and after intervention done (mean difference $=3.44,95 \% \mathrm{CI}$ : 1.80, 5.07; $\mathrm{p}<0.001)$. However, for the control camp, there was no significant improvement in practice score before and after intervention (mean difference $=$ $0.76,95 \%$ CI: $-0.47,1.98 ; p=0.225)$. The findings for the time effect on both camps were shown in Table 9.

Test of between-subjects effects indicated that there was a significant mean difference in practice score between the intervention and control group $(\mathrm{F}(1$, $186)=36.52, \mathrm{p}<0.001)$. Subsequent comparison showed that the subjects in intervention group had significantly higher mean practice score as compared to the subjects in control group (mean difference $=4.16,95 \%$ CI: $2.80,5.52 ; \mathrm{p}<$ 0.001). Table 10 showed the comparison of practice score between intervention and control camps.

\section{Discussion}

The findings from our study showed that the health education in general, was effective in improving the knowledge, attitude and practice (KAP) score. When comparing the KAP score before and six weeks after the intervention program between the intervention and control groups, it was found that there was a significant improvement in KAP score in the intervention group [12]. The same finding was seen in previous studies on KAP after the health education given [13] [14].

Among all the three domains, the knowledge domain showed marked improvement in the score in the intervention group as compared to the control group. This showed that the respondents could grasp the salient points that could improve their understanding in knowledge on leptospirosis. The method 
Table 9. Comparison of practice score between intervention and control camps based on time $(\mathrm{n}=188)$.

\begin{tabular}{ccccc}
\hline \multirow{2}{*}{ Comparison } & \multicolumn{2}{c}{ Intervention } & \multicolumn{2}{c}{ Control } \\
\cline { 2 - 5 } & $\begin{array}{c}\text { Mean difference } \\
(95 \% \mathrm{CI})\end{array}$ & p-value & $\begin{array}{c}\text { Mean difference } \\
(95 \% \mathrm{CI})\end{array}$ & p-value \\
\hline Post-pre intervention & $\begin{array}{c}3.44 \\
(1.80,5.07)\end{array}$ & $<0.001$ & $\begin{array}{c}0.76 \\
(-1.98,0.47)\end{array}$ & 0.225 \\
\hline
\end{tabular}

Repeated measures ANOVA within group analysis were applied followed by pairwise comparison with confidence interval adjustment.

Table 10. Comparison of practice score between intervention and control camps regardless of time (intervention effect).

\begin{tabular}{ccc}
\hline Comparison & Mean difference $(95 \% \mathrm{CI})$ & p-value \\
\hline Intervention-control & $4.16(2.80,5.52)$ & $<0.001$ \\
\hline
\end{tabular}

F-stat $(\mathrm{df})=36.52(1,186)$, $\mathrm{p}$-value $\leq 0.001$. Repeated measures ANOVA between group analysis was applied. Assumption of normality, homogeneity of variances and compound symmetry were checked and fulfilled. Level of significance was set at 0.05 (two-tailed).

of delivery and the type of materials that needed by them were explored using nominal group technique [15] [16]; therefore, it could be the possible explanation that they found it easier to accept the information.

For the attitude and practice domains, there was a significant difference between the intervention group and control group. And within group, there was a significant difference between pre and post intervention score in the intervention group. However, the differences in attitude and practice score were not significant in the control group before and after the intervention. It was found that the practice score in the control group was slightly lower after the intervention than the pre practice score, thus warrant the needs of having an established health education program in order to maintain a good practice in the high risk population [6] [17].

Nevertheless, previous studies on KAP changes after heath education given on other disease were reported [14] [18]. In a study done among the primary school children on the effect of nutrition education intervention, it was found that there was a significant improvement in KAP score after the health education given [14]. The post intervention KAP score was taken after six weeks of intervention cessation as done in our study. The other study that reported the same finding after a health education given on the related topic was the study done in Saudi Arabia [13]. This study was done involving the girls in a secondary school and the health education was conducted through one session. The assessment after the intervention completion was also done once, as done in our study. The researcher found that the mean scores of knowledge, attitude and practice of the intervention group were significantly higher than the control group. The same finding was illustrated in our study as well. Another study was done in Wisconsin involving 729 participants regarding the antibiotic resistance and appropriate 
antibiotic used in children [18]. This study also used printed materials and presentation on related topic as performed in our study.

There are limitations in the implementation of our health education intervention and the evaluation instrument that may influence the study findings. The data collection was done guided by a medical officer. It was possible for the respondents to feel embarrass and might concealed the truth especially questions on attitude and practice which may lead to social desirability bias. This problem was handled by assuring the respondents of their anonymity and confidentiality of individual reports. Other than that, time was the limiting factor in performing the intervention and presenting the health education in our study. The nature of job of an army personal that require the personal to be outside of the camp making it impossible to have a longer period of an intervention program. This was due to the limited time available for the army personnel to undergo the intervention program, due to the nature of their work and the work demand.

The intervention program that had been carried out was a one-off basis due to limitation of time and resources, and availability of the respondents. It was a difficult situation when we try to gather all the army personnel for the intervention program as the army personnel were not in the camp most of the time. At one particular time, part of the team had to be in the operation site or the exercise site. The training session usually takes at least seven days while during the operation, the army personnel should be in the operational site for at least two months. In addition to that, one week before and after the operation or training session, the army personnel were allowed to be on leave to be with their family in their hometown. Ideally, the intervention should be done at regular interval so that the army personnel can practice the intervention module and applies as part of the integrations into their work routine.

There may also be limitations related to the tool used as an evaluation instrument. For example, the personal hygiene practices were assessed using practice statements. Finally, the effects of the intervention were assessed six weeks after the intervention ended. Whether these positive effects will persist or are attenuated in the long term is beyond the scope of this study.

\section{Conclusion}

The present study showed that the leptospirosis health education module was effective in improving the knowledge, attitude and practice score on leptospirosis among army personnel in the intervention group. It is recommended for a more structured and regular health promotion program involving different levels of army personnel including the top management that needs to be implemented in order to ensure the sustainability of the prevention and control measures of leptospirosis among army personnel. The combination of an effective health education module and good policy at workplace can improve the seroprevalence of leptospirosis among army personnel. The finding can be used to develop health education module specific to the occupational risk groups as dif- 
ferent occupation renders, different occupational hazards and risks in leptospirosis transmission. Other than that, further research on effectiveness of the leptospirosis health education module using comparable and sustainable module of intervention should be carried out in the future. This can be done by fully utilizing the medical officers at army-based camp and their assistants by giving a proper training session on the module to them, with the aim to ensure that this program will have the continuity and can be sustained.

\section{Ethical Considerations}

The study was funded by the Research University Grant (no. 1001/PPSP/812106) and ethics approval was obtained from the Ministry of Health's Ethics Committee (NMRR-10-318-5389) and the Research Ethics Committee (Human), Universiti Sains Malaysia (Reference no: USMKK/PPP/JEPeM [219.3.(03)]).

\section{Acknowledgements}

We gratefully acknowledge the Medical Division Army Commander who gave permission for this research and all the respondents who provided us with their valuable response and cooperation in this study.

\section{Conflicts of Interest}

The authors declare no conflicts of interest regarding the publication of this paper.

\section{References}

[1] Bharti, A.R., Nally, J.E., Ricaldi, J.N., Matthias, M.A., Diaz, M.M., Lovett, M.A., Levett, P.N., Gilman, R.H., Willig, M.R., Gotuzzo, E. and Vinetz, J.M. (2003) Leptospirosis: A Zoonotic Disease of Global Importance. The Lancet Infectious Diseases, 3, 757-771. https://doi.org/10.1016/S1473-3099(03)00830-2

[2] Vanasco, N.B., Schmeling, M.F., Lottersberger, J., Costa, F., Ko, A.I. and Tarabla, H.D. (2008) Clinical Characteristics and Risk Factors of Human Leptospirosis in Argentina (1999-2005). Acta Tropica, 107, 255-258. https://doi.org/10.1016/j.actatropica.2008.06.007

[3] Richardson, D.J. and Gauthier, J.L. (2003) A Serosurvey of Leptospirosis in Connecticut Peridomestic Wildlife. Vector-Borne and Zoonotic Diseases, 3, 187-193. https://doi.org/10.1089/153036603322662174

[4] Moore, G.E., Guptill, L.F., Glickman, N.W., Caldanaro, R.J., Aucoin, D. and Glickman, L.T. (2006) Canine Leptospirosis, United States, 2002-2004. Emerging Infectious Diseases, 12, 501-503. https://doi.org/10.3201/eid1203.050809

[5] Rahim, S.M., Aziah, B.D., Nazri, S.M., Azwany, Y.N., Habsah, H., Zahiruddin, W.M., Zaliha, I. and Rusli, A.M. (2011) Town Service Workers' Knowledge, Attitude and Practice towards Leptospirosis. Brunei Darussalam Journal of Health, 5, 12.

[6] Brown, P.D., McKenzie, M., Pinnock, M. and McGrowder, D. (2011) Environmental Risk Factors Associated with Leptospirosis among Butchers and Their Associates in Jamaica. International Journal of Occupational and Environmental Medicine, 2, 47-57. 
[7] Pavli, A. and Maltezou, H.C. (2008) Travel-Acquired Leptospirosis. Journal of Travel Medicine, 15, 447-453. https://doi.org/10.1111/j.1708-8305.2008.00257.x

[8] Dupont, W.D., Walton, D. and Plummer, J. (2009) PS: Power and Sample Size Calculation.

[9] Raisuddin, N.S. (2009) Validation of Knowledge, Attitude and Practice (KAP) Questionnaire among Army Personnel in Terengganu, Universiti Sains Malaysia, Kubang Kerian.

[10] Dimitrov, D.M. and Rumrill, P.D. (2003) Pretest-Posttest Designs and Measurement of Change. Work, 20, 159-165.

[11] Naing, N., et al. (2011) Repeated Measures Analysis of Variance. Institute of Postgraduate Studies, Universiti Sains Malaysia, Kubang Kerian.

[12] Rattanasaeng, W. and Soommart, V. (2007) The Effective of Leptospirosis Prevention and Control Model with Community Participation: Case Study in Suwannapum District, Roi-et Province, 2005. Khon Kaen Medical Journal, 31, 13.

[13] Fetohy, E.M. (2007) Impact of a Health Education Program for Secondary School Saudi Girls about Menstruation at Riyadh City. Journal of Egypt Public Health Association, 82, 106-126.

[14] Shariff, Z.M., Bukhari, S.S., Othman, N., Hashim, N., Ismail, M., Jamil, Z., Kasim, S.M., Paim, L., Samah, B.A. and Hussein, Z.A.M. (2008) Nutrition Education Intervention Improves Nutrition Knowledge, Attitude and Practices of Primary School Children: A Pilot Study. International Electronic Journal of Health Education, 11, 119-132.

[15] Harvey, N. and Holmes, C.A. (2012) Nominal Group Technique: An Effective Method for Obtaining Group Consensus. The International Journal of Nursing Practice, 18, 188-194. https://doi.org/10.1111/j.1440-172X.2012.02017.x

[16] Roeden, J.M., Maaskant, M.A. and Curfs, L.M. (2012) The Nominal Group Technique as an Evaluation Tool for Solution-Focused Coaching. Journal of Applied Research in Intellectual Disabilities, 25, 588-593. https://doi.org/10.1111/j.1468-3148.2012.00696.x

[17] Robertson, H., Hanna, J. and Brookes, D. (2002) Leptospirosis Annual Report 2002, Tropical Public Health Unit Network, Queensland.

[18] Trepka, M.J., Belongia, E.A., Chyou, P.H., Davis, J.P. and Schwartz, B. (2001) The Effect of a Community Intervention Trial on Parental Knowledge and Awareness of Antibiotic Resistance and Appropriate Antibiotic Use in Children. Pediatrics, 107, E6. https://doi.org/10.1542/peds.107.1.e6 